УДК: 021.4+37.016:808.1

\author{
Владимир Гладымев, \\ ORCID iD 0000-0001-7232-4184 \\ доктор педагогических наук, профессор, \\ профессор кафедры теории и методики \\ языково-литературного и художественно-эстетического \\ образования Николаевского областного \\ института последипломного педагогического образования \\ ул. Адмиральская, 4-а, 54001, г. Николаев, Украина \\ volodymyr.hladyshev@moippo.mk.ua
}

\title{
ОБЩАЯ ХАРАКТЕРИСТИКА БИБЛИОТЕРАПЕВТИЧЕСКОГО ЧТЕНИЯ КАК ИНСТРУМЕНТА ПСИХОЛОГИЧЕСКОЙ САМОПОМОЩИ УЧИТЕЛЯ
}

Статья представляет собой общую характеристику библиотерапевтического чтения, рассматриваемого в качестве инструмента психологической самопомоши учителя. Рассмотрена специфика библиотерапии, выделены «факторы риска», обусловленные спецификой профессии учителя, проанализировано их влияние на психологическую устойчивость учителя. Сделан анализ основных профессиональных и личностных факторов, снижающих психологическую устойчивость учителя, предложены варианть применения библиотерапевтического чтения, которые обеспечивают «эффект невалямки» - умение с наименьшими эмоционально-репутационными потерями восстанавливаться после психологических «провалов», избежать которых никто не в состоянии.

Ключевые слова: библиотерапия; запрос; психологическая самопомощь;; учитель; чтение; «эффект неваляшки».

(C) Гладышев В. В., 2021

Введение. Несмотря на то, что обращение к книге с целью восстановления «душевного здоровья» предлагалось ещё в античности, а сам термин «библиотерапия» появился в научном обиходе в 1916-м году, в бывшем СССР признание этого метода воздействия на человека произошло достаточно поздно.

Основателем библиотерапии в СССР считают руководителя психотерапевтической клиники Вильнюсского центра психического здоровья Александра Алексейчика, который дал следующее определение этого явления: «Библиотерапия - специальное коррекционное воздействие на клиента с помощью чтения специально подобранной литературы в целях нормализации или оптимизации его психического состояния» (Режим доступа на 16.09.20202: https:// thelib.info/psihologiya/1928810-obshhaya- harakteristika-metoda/).

Спецификой библиотерапии принято считать то, что эта наука находится на стыке медицины и библиотечного дела. В этой связи особое внимание уделяется литературным произведениям как основе целенаправленного воздействия на личность с целью позитивного влияния на её психическое состояние.

В начале нашего века интерес к библиотерапии значительно усилился, поскольку стало понятно: воздействие психотерапевтов на личность может оказаться эффективным только в том случае, когда оно носит комплексный характер, когда личность принимает самое активное участие в собственном «исцелении». Это подразумевает готовность работать над собой, осуществление своеобразной самопомощи и обращение к литературным произведе- 
ниям как носителям морально-эстетических ценностей становится эффективной формой «проживания» самых различных состояний, в которых находятся герои этих произведений.

На постсоветском пространстве всплеск интереса к библиотерапии нашёл выражение в появлении значительного числа работ, в которых рассматриваются теоретические и практические аспекты её применения. Поскольку библиотерапия, как уже отмечалось, теснейшим образом связана с библиотечным делом, её изучение предусмотрено в рамках подготовки библиотечных работников высшей школой.

Рассмотрению библиотерапии как фактора эффективной профессиональной подготовки библиотечных работников посвящены фундаментальные труды доктора педагогических наук Ю. Н. Дрешер (Дрешер Ю. Н., 2007; Дрешер Ю. Н., 2008).

Различные аспекты связи библиопсихологии и библиотерапии рассматриваются в исследовании под редакцией Н. С. Лейтес, Н. Л. Карпова, О. Л. Кабачек (Лейтес Н. C., 2005).

В своих лекциях польский учёный И. Борецка (Борецка И., 2006) рассматривает наиболее актуальные проблемы теории и практики библиотерапии, предлагает эффективные варианты её применения в деятельности библиотечных работников.

Научно-популярное рассмотрение основ библиотерапии, предназначенное для библиотечных работников, представлено в работе Е. О. Мишуковой (Мишукова Е. О., 2011).

Британские библиотерапевты Э. Берту и С. Элдеркин (Берту Э., Элдеркин С., 2016) представили обзор мировой литературы под углом зрения использования рассматриваемых литературных произведений как основы для библиотерапевтического воздействия на личность. Эта работа имеет и филологическую, и библиотерапевтическую ценность.

В то же время авторы многочисленных работ по библиотерапии сосредоточили своё внимание на особенностях литературных произведений и методах работы с ними, практически не затрагивая неповторимость и уникальность каждой личности, с которой проводится библиотерапия. Полагаем, такой подход заметно снижает эффективность библиотерапии, поскольку восприятие каждого литературного произведения отдельной личностью определяется совокупностью факторов, сформировавших эту личность, и её личностно-психологическими запросами.

Особенность работы учителя заключается в том, что профессия накладывает очень глубокий отпечаток на личность. Учитель - профессия в высшей степени «энергозатратная», соответственно и психологическое восстановление учителя чрезвычайно важно как для учителя-человека, так и для человека-учителя.

Поскольку в рамках реализации программы «Новая украинская школа», как справедливо отмечает В. И. Шуляр (Шуляр В. И., 2019; Шуляр В. И., 2020), важнейшим «ресурсом» является именно учитель, проблема психологической устойчивости учителя, его способности быстро восстанавливаться, становится одной из важнейших для обеспечения эффективности профессиональной деятельности учителя и его полноценной, гармоничной жизни.

Именно отмеченные выше моменты и обусловили актуальность статьи и её цели.

Цели статьи. Целями статьи является:

1. Определение специфики библиотерапевтического чтения применительно к особенностям профессиональной деятельности под углом зрения формирования у педагогов «эффекта неваляшки», подразумевающего быстрое и без значительных эмоционально-репутационных потерь восстановление после переживания сложных психологических ситуаций.

2. Определение основных «личностных» запросов учителя (условно названных «профессиональные» и «индивидуальные») и путей поисков ответов на них с помощью библиотерапевтического чтения, 
понимаемого как эффективный инструмент психологической самопомощи учителя.

3. Определение наиболее эффективных путей совершенствования методики библиотерапевтического чтения учителя (индивидуальный и коллективный аспекты).

Учитель и библиотерапевтическое чтение. При определении основных «зон риска» в работе учителя мы исходим из того, что особенности профессии налагают повышенные обязательства на поведение учителя и его отношения с окружающими. Соответственно, это приводит к тому, что в любом общении учитель потенциально уязвим: его поведение может быть превратно истолковано собеседниками. Для учителя характерны повышенная напряжённость в отношениях, невозможность забыть о «взгляде со стороны». Общение требует усиления самоконтроля, что, в свою очередь, достигается благодаря мобилизации психических ресурсов. Как следствие учитель тратит много сил на «поддержание формы», и ему необходимы источники «возобновления психической энергии», одним из которых становится библиотерапевтическое чтение.

Оно отличается от обычного чтения тем, что изначально носит «запросный характер», связанный с переживаемой учителем ситуацией. В то же время профессия учителя, предполагающая целенаправленную работу с разного рода литературой, подготовила учителя к библиотерапевтическому чтению художественных произведений. Следовательно при правильном определении «запроса» и адекватном выборе литературного произведения библиотерапевтическое чтение его учителем обеспечивает положительное воздействие на личность и помогает быстрее восстановить эмоциональный комфорт.

Библиотерапевтическое чтение позволяет читателю не столько усвоить определённую информацию, сколько эмоционально прожить ситуации, в которых находятся персонажи произведения, погрузиться в созданный писателем мир, и сквозь при- зму этих переживаний увидеть себя, своё душевное состояние, свои собственные переживания. Вследствие этого отношение к себе, к собственным проблемам становится более осознанным, сравнение с «чужой» жизнью становится плодотворной формой самопознания.

Основная трудность заключается в том, что определить «личностный запрос» самому человеку очень часто не представляется возможным. И не только учителю, любому человеку, потому что симптомы и «болезнь» могут быть весьма опосредованно связаны между собой, и выявить эту связь самому практически невозможно. «Глубинные причины происходящего» (Гладышев В. В., Гладышева С. А., 2020, c. 16) с человеком могут быть до такой степени далеки от симптомов проявления дискомфорта, что только помощь специалиста может стать ответом на вопрос: «Что со мной происходит?». Поэтому учителю следует получить психологическую консультацию, в ходе которой, не исключено, он узнает о себе самом много нового.

Для того, чтобы любое действие было результативным, необходимо понимать, какую цель мы ставим перед собой. И понимание сущности «запроса», и последующее библиотерапевтическое чтение не являются самоцелью - это шаги на пути к обретению более высокой эмоциональной устойчивости, которая условно носит название «эффект неваляшки» (Гладышев В. В., Гладышева С. А., 2020, С. 18-21). Его сформированность предполагает как минимум наличие двух качеств: a) адекватная оценка происходящего; б) как можно более быстрое восстановление эмоционального равновесия после «психологического провала».

Поскольку библиотерапевтическое чтение - процесс предельно индивидуализированный, учителя следует ознакомить с его методикой. Однако это знакомство не может быть оторвано от тех литературных произведений, обращение к которым обеспечивает процесс позитивного влияния чтения на личность. Особое значение при- 
обретает индивидуальный список произведений для чтения, который составляется учителем исключительно для себя самого и поэтому носит предельно личностный характер.

Составление такого списка - дело, можно сказать, всей жизни, потому что произведения, которые воспринимаются нами как личностно значимые, могут появиться в любое время и в любом возрасте. Они просто, как выражается современная молодёжь, «цепляют», вызывают эмоциональный отклик, вызывают желание обращаться к ним снова и снова.

Важный момент: при составлении такого списка нет и не может быть никаких «оглядок» на чужое мнение. Прислушиваться к советам, конечно, необходимо, однако только сам учитель определяет, какие произведения по-настоящему значимы для него.

Опыт показывает, что среди таких произведений могут оказаться и произведения массовой культуры, которые не признаются «серьёзной» литературой. Но для человека, которого они привлекают, такого рода оценки не должны иметь никакого значения. Список составляем мы для себя, стало быть, и правы в том, что выбрали те произведения, которые выбрали.

Методика библиотерапевтического чтения включает в себя 4 этаnа:

1. Определение «личностного запроса», с которым мы обращаемся к литературе вообще.

2. Выбор художественного произведения или фрагмента из произведения, чтение которого позволит «эмоционально погрузиться» в переживаемое персонажами состояние, причём это состояние максимально приближено (на уровне проживания) к тому «личностному запросу», с которым мы обращаемся.

3. Собственно чтение литературного произведения или его фрагмента. На этом этапе всё определяется самим учителем, которому необходимо организовать максимально комфортное (для него самого!) общение с книгой.
4. Четвёртый этап не должен носить фиксированный характер, его условно можно назвать «постчтением». В библиотерапии на этом этапе клиент взаимодействует с психотерапевтом, однако в случае с библиотерапевтическим чтением учителя речь идёт об «автобиблиотерапии», самопомощи, поэтому учителю следует соотнести первоначальный импульс, ставший причиной обращения к чтению, свой «личностный запрос» и те результаты, которые получены в результате чтения. Фактически этот этап начинается уже в процессе чтения.

Основные «личностные запросы» учителя и работа с ними в процессе библиотерапевтического чтения. Как уже отмечалось, «личностные запросы» учителя условно разделяются на «профессиональные» и «индивидуальные».

К «профессиональным» относятся запросы, которые регулируются следующими отношениями:

1. На своём ли месте я оказался? (Я и моя профессия).

2. Я и коллеги.

3. Я и родители учеников.

4. Я и ученики.

К «индивидуальным» относятся запросы, которые регулируются следующими понятиями:

1. Я и моё здоровье.

2. Я и мои зоны ответственности.

3. Я и одиночество.

4. Я и моя семья (партнёр и дети).

5. Я и моё финансовое благополучие.

Напомним: разделение «личностных запросов» на «профессиональные» и «индивидуальные» достаточно условно именно потому, что профессия учителя, как отмечалось, очень сильно влияет на личность, её характер, самооценку, отношения с близкими людьми.

При работе с «личностными запросами» первой группы определяющим фактором становится потребность сформировать у учителя точное понимание зоны своей профессионально-личностной ответственности, что обеспечивает эффективное вы- 
полнение служебных обязанностей.

Проблема выбора профессии не ограничивается финансовым аспектом. Здесь речь идёт о самореализации, о том, как воспринимает учитель свою работу и себя на работе. В любом коллективе неизбежны конфликтные ситуации, но человек, который «сел не в свои сани», занимается делом, к которому не лежит душа, будет тяготиться своей работой, самим собой в качестве учителя.

Отношения с коллегами не могут быть ровными всегда, поэтому учитель должен быть готов к конфликтным ситуациям. Как выйти из них, сохранив «лицо» и здоровье? Где заканчивается право коллег на вмешательство в твою профессиональную деятельность и личную жизнь? Как отстаивать себя в коллективе? Эти и множество других вопросов возникают в жизни учителя, от ответов на них зависит, насколько комфортной будет профессиональная деятельность.

В процессе выстраивания отношений с родителями учащихся учитель неизбежно сталкивается с конфликтом интересов: каждый родитель считает своего и только своего ребёнка особенным, тогда как для учителя все учащиеся - особенные! Отношения с родителями предполагают доверительный характер, но нередко они становятся для учителя проблемными, и умение избегать проблем - важный фактор взаимопонимания педагога и родителей.

Наконец, отношения с учениками. Здесь опыт учителю и помогает, и мешает. Так происходит потому, что каждое новое поколение учащихся обязательно отличается от своих предшественников. Причём отличия эти носят как позитивный, так и деструктивный характер. Следовательно, учителю необходимо опираться на имеющийся у него опыт общения со школьниками, но и одновременно быть открытым к восприятию, осмыслению и приятию того нового, что преподносит нам жизнь вместе с каждым новым учеником.

В рамках рассмотренных выше отношений правильно организованное и си- стематически применяемое библиотерапевтическое чтение способно обеспечить учителю эффективную психологическую самопомощь.

При работе с «личностными запросами» второй группы внимание смещается в сторону «внерабочих» отношений учителя с окружающими. Чтобы понять эти проблемы, надо вспомнить, что для личности фундаментальной ценностью является безопасность - собственная и близкого окружения.

Забота о физическом и психологическом здоровье естественна для любого нормального человека, поскольку именно здоровье является фундаментом безопасности, никакие материальные блага не помогут больному человеку ощущать себя комфортно.

Умение правильно строить свои отношения с окружающими, не перебирать на себя чужие проблемы, одновременно не избегая своей личной ответственности, формирование адекватной самооценки первейшая задача учителя и любого человека. В конечном итоге, это обеспечивает безопасность и доверительность в отношениях.

Проблемы одиночества и семьи взаимосвязаны, при этом только от самого человека зависит, сможет ли он построить крепкую семью, в которой отношения между членами будут тёплыми и уважительными, или же его попытки выйти из одиночества приведут к «одиночеству в семье», которое по своему воздействию на личность изначально деструктивно.

Наконец, материальный аспект жизни учителя, о котором до недавних пор не принято было говорить вслух. Однако он имеет важнейшее значение для личности учителя и для его профессионального и личностного роста. В данном случае он соприкасается с проблемой выбора профессии: является ли для учителя его работа только способом заработать деньги или же она становится достойно оплачиваемой формой самореализации в процессе общественно-полезной деятельности. 
Детальное, на уровне конкретных примеров библиотерапевтического чтения, рассмотрение изложенных выше проблем предлагается в изданной МОИППО книге Владимира и Светланы Гладышевых (Гладышев В. В., Гладышева С. А., 2020).

Выводы. Рассмотрение проблем библиотерапевтического чтения как инструмента психологической самопомощи учителя позволяет сделать следующие основные выводы:

- специфика библиотерапевтического чтения применительно к особенностям профессиональной деятельности под углом зрения формирования у педагогов «эффекта неваляшки» обусловлена единством личностного и профессионального начал в структуре личности учителя, что подразумевает более высокий уровень готовности учителя к использованию библиотерапевтического чтения как особой формы психологической самопомощи;

- основные «личностные» запросы учителя (условно названные «профессиональными» и «индивиду- альными») охватывают широкий круг личностно-профессиональных проявлений учителя, и это обеспечивает эффективность возможного применения библиотерапевтического чтения в качестве инструмента психологической самопомощи учителя.

Основными перспективными направлениями дальнейших исследований использования библиотерапевтического чтения как инструмента психологической самопомощи учителя представляются следующие:

- поиски наиболее эффективных для библиотерапевтического чтения художественных произведений применительно к «личностным запросам» учителей;

- совершенствование содержания и форм работы по библиотерапевтическому чтению учителя на каждом из его этапов;

- подготовка методических материалов для учителя по организации им библиотерапевтического чтения.

\section{ЛИТЕРАТУРА}

1. Берту Э. Книга как лекарство : скорая литературная помощь от А до Я / Э. Берту, С. Элдеркин . - Москва : Синдбад. - 2016. - 490 с.

2. Библиопсихология и библиотерапия ; [под. ред. Н. С. Лейтес, Н. Л. Карпова, О. Л. Кабачек]. - Москва : Шк. б-ка. -2005. - 479 с.

3. Борецка И. Библиотерапия. Лекции / И. Борецка. - Лекции. - Гродно : ГрГУ, 2007. - 100 с. Пер. с польского И. Ф. Притульчик.

4. Гладышев В. В. Библиотерапевтическое чтение - инструмент психологической самопомощи учителя : справочные материалы / В. В. Гладышев, С. А. Гладышева. - Николаев : НОИППО, 2020. - 96 с.

5. Дрешер Ю. Н. Библиотерапия. Полный курс : учеб. пособие / Ю. Н. Дрешер. М. : «Издательство ФАИР». - 2007. - 560 с.

6. Дрешер Ю. Н. Библиотерапия : теория и практика : учебное пособие / Ю. Н. Дрешер. - СПб. : «Профессия». - 2008. - 269 с.

7. Мишукова Е. О. Лечение книгой, или Основы библиотерапии / Е. О. Мишукова. - Москва : ЦБС № 3 ЮАО, Библиотека - филиал № 172 «Просвещение трудящихся», 2011. -19 c.

8. Шуляр В. І. Стратегії організації освітнього процесу : до реалізації Концепції «Нова українська школа» / В. І. Шуляр // Директор школи. - 2019. - 7 (847). - С. 93-104.

9. Шуляр В. І. Учитель як людський ресурс Нової української школи : навчальний 
посібник / В. І. Шуляр. - Миколаїв : МОІППО, 2020. - 50 с.

10. Режим доступа на 16.09.20202: https://thelib.info/psihologiya/1928810-obshhayaharakteristika-metoda/

\title{
БІБЛІОТЕРАПЕВТИЧНЕ ЧИТАННЯ - ІНСТРУМЕНТ ПСИХОЛОГІЧНОӦ САМОДОПОМОГИ ВЧИТЕЛЯ
}

\author{
Гладишев Володимир, \\ доктор педагогічних наук, професор, \\ професор кафедри теорії й методики \\ мовно-літературної та художньо-естетичної освіти \\ Миколаӥвський обласний інститут \\ післядипломної педагогічної освіти \\ вул. Адміральска, 4-а, 54001, м. Миколаїв, Україна \\ volodymyr.hladyshev@moippo.mk.ua
}

Стаття є загальною характеристикою бібліотерапевтичного читання, яке розглядається як інструмент психологічної самодопомоги вчителя. Розглянуто спечифіку бібліотерапії, визначені «чинники ризику», щуо зумовлені специфікою професії вчителя, проаналізовано їхній вплив на психологічну стійкість учителя. Зроблено аналіз провідних професійних та особистісних чинників, щу знижують психологічну стійкість учителя, запропоновані варіанти використання бібліотерапевтичного читання, щзо забезпечують «ефект неваляйки» - уміння з найменшими емоційно-репутаційними втратами відновлятися після психологічних провалів, уникнути яких неможливо.

Ключові слова: бібліотерапія; «ефект неваляйки»; запит; психологічна самодопомога; учитель; читання.

\section{BIBLIOTHERAPEUTIC READING AS A TOOL FOR PSYCHOLOGICAL SELF-HELP OF A TEACHER}

\author{
Hladyshev Volodymyr, \\ Doctor of Pedagogical Sciences, Professor \\ Department of Theory and Methods of Language, \\ Literature, Art and Aesthetic Education \\ Mykolaiv In-Service Teachers Training Institute \\ 4-a Admiralska Street, Mykolaiv, 54001, Ukraine \\ volodymyr.hladyshev@moippo.mk.ua
}

The article is devoted to the general issues and methods of reading therapy (or bibliotherapy) used by a teacher. This kind of reading is defined as one of the most significant and most accessible tools for psychological teacher self-help. As a teacher's personality is extremely meaningful, the problem of teachers' psychological comfort nowadays becomes really important.

The characteristic of bibliotherapy is given, and the main difference from ordinary reading is determined. That is a peculiar «request» referred to in the book. The «risk zones» in the teaching profession are defined, the essence of «weeble effect» is explained, the role of rapid emotional teacher's recovery after the inevitable emotional failures is emphasized.

We determined the common features of literary works list for therapeutic reading, highlighted the stages of this kind of reading, analyzed their specifics, and the role of each 
stage in the overall reading process. The personal mode of making a list and the process of bibliotherapy is emphasized. We defined the range of the main teacher's "personal requests», which are conditionally divided into related "professional» and «individual» ones, and offered some options for possible work on each of them. They are based on the reading of classical literature because it demonstrates the possibilities of such therapy to the full extent. Special attention is paid to the importance of harmony in family relationships: with a partner and children because it is the basis for the productive activity of a teacher. The conclusion of the article is based on its content and covers the most general patterns of the teacher's bibliotherapeutic reading.

Keywords: bibliotherapy; psychological self-care; reading; request; teacher; «weeble effect».

\section{REFERENCES}

1. Bertu, Je. \& Jelderkin, S. (2016). Kniga kak lekarstvo: skoraja literaturnaja pomoshh ot $A$ do $J a$ [A book as medicine: emergency literary aid from A to Z]. Moskva: Sindbad (rus).

2. Borecka, I. (2007). Biblioterapija. Lekcii [Bibliotherapy. Lections]. (I. F. Pritulchik, Trans.). Grodno: GrGU (rus).

3. Dresher, Ju. N. (2007). Biblioterapija. Polnyj kurs [Bibliotherapy. Complete book]. Moskva: FAIR (rus).

4. Dresher, Ju. N. (2008). Biblioterapija: teorija i praktika [Bibliotherapy: theory and practice]. Sankt-Peterburg: Professija (rus).

5. Hladyshev, V. V. \& Hladysheva, S. A. (2020). Biblioterapevticheskoe chtenie instrument psihologicheskoj samopomoshhi uchitelja [Bibliotherapeutic reading - a tool for psychological self-help of teachers]. Nikolaev: NOIPPO (rus).

6. Lejtes, N. S., Karpova, N. L. \& Kabachek, O. L. (2005). Bibliopsihologija ibiblioterapija [Bibliopsychology and bibliotherapy]. Moskva: Shkolnaja biblioteka (rus).

7. Mishukova, E. O. (2011). Lechenie knigoj, ili Osnovy biblioterapii [Treatment of book, or the Basics of bibliotherapy]. Moskva: Prosveshhenie trudjashhihsja (rus).

8. Retrieved from: https://thelib.info/psihologiya/1928810-obshhaya-harakteristikametoda/ (rus).

9. Shuliar, V. I. (2019). Stratehii orhanizatsii osvitnoho protsesu: do realizatsii Kontseptsii «Nova ukrainska shkola» [Strategies for organizing the educational process: towards the implementation of the «New Ukrainian school» Concept]. Dyrektor shkoly, 7 (847), 93-104 (ukr).

10. Shuliar, V. I. (2020). Uchytel yak liudskyi resurs Novoi ukrainskoi shkoly [Teacher as a human resource of the New Ukrainian school]. Mykolaiv: MOIPPO (ukr). 